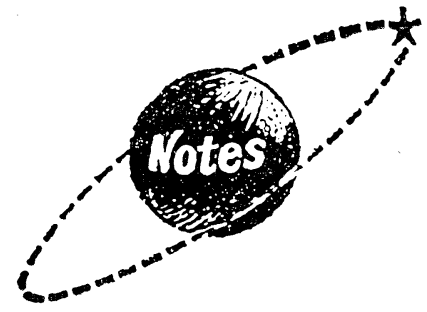

北海道工業開発試験所*

名古屋大学**

\section{高温下における $\mathrm{HCl} . \mathrm{SO}_{2}$}

\section{吸収剂の探索}

流動層を用いて都市ゴミなど $\mathrm{Cl}, \mathrm{S}$ 分を含んだ然料 を高温下で燃焼する際に発生する $\mathrm{HCl}, \mathrm{SO}_{2}$ を流動粒 子により吸収除去する吸収剂を探索する目的で，4 種 類の試料による吸収試験を石英製の小型反応器を用い て行った。まず， $\mathrm{HCl}$ の吸収効果に重点を置き，さら に煆焼の有無による吸収率の変化と $\mathrm{SO}_{2}$ との同時吸 収について検討を加えた。

\section{1. 実験}

\section{1 装置与よび方法}

反応管は，試料充填部の内径が $18 \mathrm{~mm}$ ，高さが約 100 $\mathrm{mm}$ の石英製で，管内には試料保持用の粒状セラミッ クスをたは石英フィルターを取りつけた。吸収剤の充 填層高は約 $10 \mathrm{~mm}$ である。実験は，温度一定の充填層 に濃度調整したガスを流して行った。温度は $800^{\circ} \mathrm{C}$, 流量 $\mathrm{Q} は 1 \mathrm{~N} \ell / \mathrm{min}$ であり，このときの空間時間（見

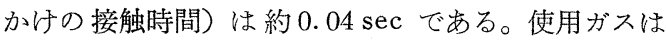
$\mathrm{HCl}, \mathrm{SO}_{2}, \mathrm{O}_{2}, \mathrm{CO}_{2}$ で, 入口濃度はそれぞれ $\mathrm{Ci}_{\mathrm{HCl}}=$

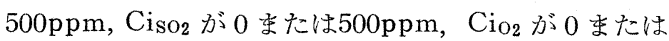
$4 \%, \mathrm{Ci}_{\mathrm{CO}_{2}}$ が0または 0 ま％，バランスガスはアルゴ ンである。

\section{2 吸収剂}

実験に用いた吸収剤は，石灰石ドロマイトニニッケ
-1982. 6. 24 受理一

出口 明，河内山康司，細田 英雄

三浦 正勝，平間 利昌，西崎 寛樹

堀尾 正䩲
ル鉱石およびオリビンサンドの 4 種類で, それらの化 学組成の分析値をTable 1 に示す。これらを選定した 理由は, 流動化時に粉化が少ないこと, 塩化水素を吸 収して生成した塩化物の融点が高く，燃焼炉内での溶 融によるトラブルが起きないことの 2 点である。粒径 はオリビンサンドでは $0.5 \sim 1.0 \mathrm{~mm}$ ，との他の場合は $1.0 \sim 2.38 \mathrm{~mm}$ である。試料は, 温度 $900^{\circ} \mathrm{C}$, 酸素濃度 $19.2 \%$ (残りはアルゴンガス) で 5 時間层焼した。

\section{2. 結果と考察}

温度 $800 \sim 900^{\circ} \mathrm{C}, \quad \mathrm{Ci}_{\mathrm{HCl}}=500 \mathrm{ppm}, \mathrm{Q}=1 \mathrm{~N} \ell / \min の$ 条件下で測定した各吸収剤の $\mathrm{HCl}$ 吸収率 $\mathrm{X}_{\mathrm{HCl}}$ の初 期值 $\left(\mathrm{X}_{\mathrm{HC} 1}\right) \mathrm{i}$ を Table 1 の右端に示した。なお $\mathrm{X}_{\mathrm{HC} 1}$ は次式により定義した。

$$
\mathrm{X}_{\mathrm{HCl}}=\frac{\mathrm{Ci}_{\mathrm{HCl}}-\mathrm{CoHCl}_{\mathrm{H} 1}}{\mathrm{Ci}_{\mathrm{HCl}}}
$$

$\mathrm{CoHCl}$ は反応管出口の $\mathrm{HCl}$ 濃度を表わす。 $\mathrm{Ni}$ 鉱 石とオリビンサンドの吸収率は約10\%と低かった。こ れに対してドロマイトと石灰石の吸収率は温度が高く なるとわずかに低下する傾向があるが，900 C でも 80 \%以上であった。そこで，ドロマイトと石灰石の $\mathrm{HCl}$ 吸収率の経時変化を測定した。その結果をFig. 1 亿示

Table 1 Analyses of absorbents (wt $\%$ )

\begin{tabular}{lcccccccc}
\hline & $\mathrm{CaO}$ & $\mathrm{MgO}$ & $\mathrm{SiO}_{2}$ & $\mathrm{Al}_{2} \mathrm{O}_{3}$ & $\mathrm{Fe}_{2} \mathrm{O}_{3}$ & $\mathrm{Ni}$ & Ig-Loss & $\left(\mathrm{X}_{\mathrm{HCl}}\right)$ i $(\%)$ \\
\hline limestone & 55.4 & 0.2 & 0.3 & 0.03 & 0.02 & - & 43.6 & $80 \sim 95$ \\
dolomite & 33.2 & 18.7 & 2.0 & & 0.3 & - & 45.7 & $80 \sim 95$ \\
Ni-ore & 0.2 & 24 & 42 & - & 20 & 2.6 & 10 & $10 \sim 15$ \\
olivine-sand & - & 48.6 & 40.9 & 0.9 & 7.4 & - & 0.6 & $10 \sim 15$ \\
\hline
\end{tabular}

$\left(\mathrm{X}_{\mathrm{HCl}}\right)_{\mathrm{i}}$ : initial HCl absorption efficiency

*第 3 部 札幌市豊平区月寒東 2 条 17 丁目 **工学部鉄鋼工学科 名古屋市千種区不老町 


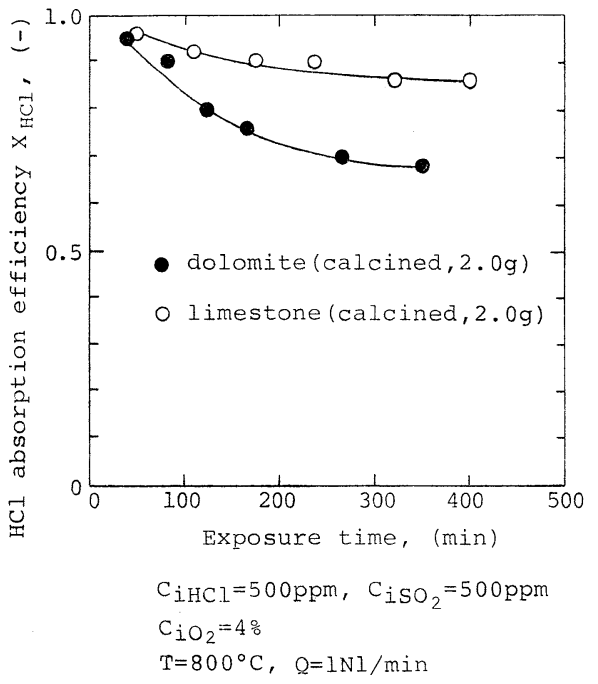

Fig. 1 Variations of $\mathrm{HCl}$ absorption efficiency with exposure time

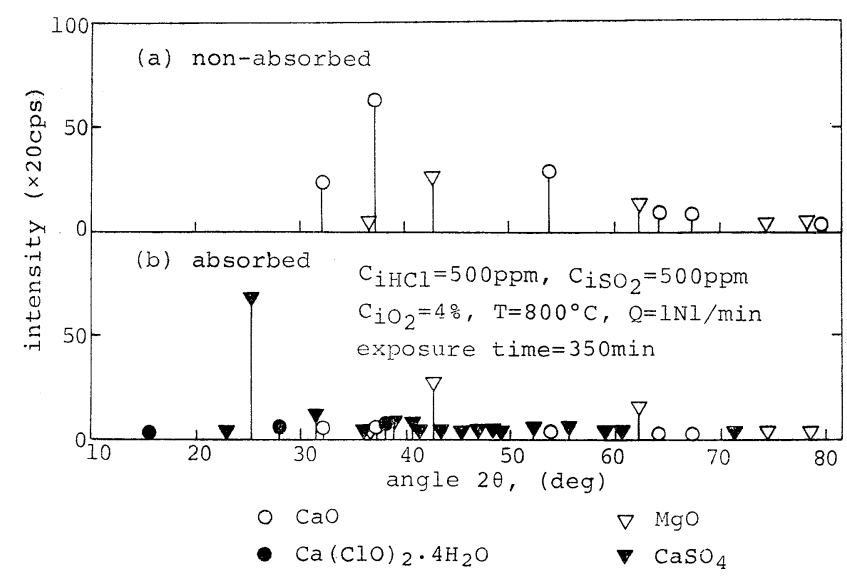

Fig. $2 \mathrm{X}$-ray diffraction patterns of dolomite

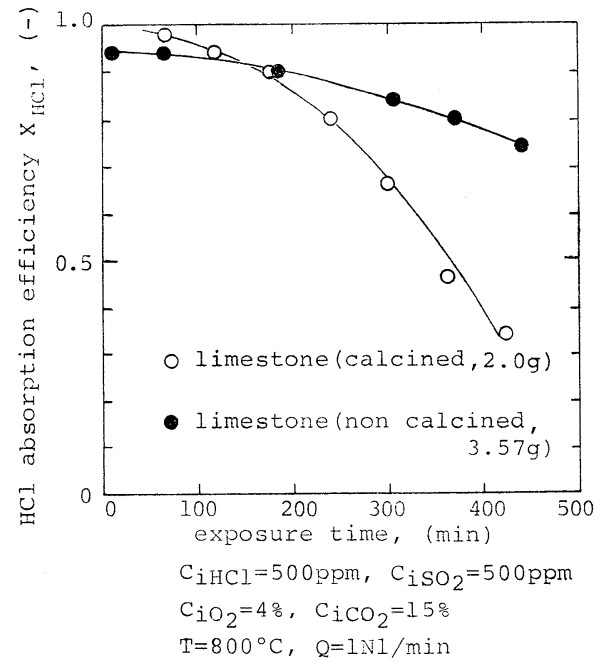

Fig. 3 Variations of $\mathrm{HCl}$ absorption efficiency with exposure time

$\mathrm{HCl}$ の吸収には淘とんど関与していな いことが推測される。ドロマイト中には $\mathrm{MgO}$ が 30wt \%以上含まれているため, 吸収時間の経過とともに石灰石よりす东 やかた $\mathrm{HCl}$ 吸収能が低下したと考兄ら れる。

以上の結果から，本実験で使用した吸 収剂の中では石灰石の $\mathrm{HCl}$ 吸収能がも っとも高いことがわかった。そこで石灰 石の $\mathrm{HCl}$ 吸収に対する层焼つ効果につ いて検討した。Fig. 3 に煆焼した石灰石 $(\mathrm{CaO})$ と煆焼しない石灰石 $\left(\mathrm{CaCO}_{3}\right)$ の $\mathrm{HCl}$ 吸収率の経時変化を示す。この実験 では， $\mathrm{Ca}$ 量が等しくなるように $\mathrm{CaO} の$ 場合は2.0 g, $\mathrm{CaCO}_{3}$ の場合は3.57 g を
す。ここでは実際の然焼の際に発生し,さらに HCl の 吸収と競合する可能性がある $\mathrm{SO}_{2}$ を加えている。ドロ マイトと石灰石の初期吸収率はほとんど等しいが，時 間の経過にともなう $\mathrm{HCl}$ 吸収率の低下はドロマイト の方がすタやかである。

そこで，この経時変化の違いの原因を検討するため $\mathrm{HCl}$ 吸収前後のドロマイトをX線回折装置 $(\mathrm{Cu}$ 対陰 極）によって分析した結果を Fig.2 に示す。 $\mathrm{CaO}$ の 回折ピーク高さを吸収前後で比較すると，吸収後つ方 が著しく低く，塩化物々しては $\mathrm{Ca}(\mathrm{ClO})_{2} \cdot 4 \mathrm{H}_{2} \mathrm{O}$ が 同定されている。一方， $\mathrm{MgO}$ のピーク高さは吸収前 後で汪とんど変わらず，をた吸収後の試料からは $\mathrm{Mg}$ の塩化物が検出されていない。こことから，MgOは
反応管に充填した。初期吸収率は $\mathrm{CaO}$ の方がわずか に高い。しかし吸収率の低下が早く, 約 400 分後の $\mathrm{HCl}$ 吸収率は $\mathrm{CaCO}_{3}$ の約 2 分の 1 になる。

これまでは $\mathrm{HCl}$ の吸収だけについて検討してきた が，然料中に S分も含まれる場合を考慮し， $\mathrm{HCl}$ と $\mathrm{SO}_{2}$ が共存する場合の $\mathrm{SO}_{2}$ の吸収能についても検討 した。Fig. 4 には, 煙道摸擬排ガス $\left(\mathrm{Ci}_{2}=4 \%, \mathrm{Ci}_{\mathrm{CO} 2}\right.$ =15\%）中に $\mathrm{HCl}$ だけ， $\mathrm{SO}_{2}$ だけ，拈よび両者を含 む場合の吸収試験結果を比較して示す。吸収剤には, 吸收率の経時変化が少なかった $\mathrm{CaCO}_{3}$ 用いた。 $\mathrm{SO}_{2}$ 濃度は $\mathrm{HCl}$ と同様にガス検知管（ドレーダル）を用 いて測定した。横軸の固体の反応率 $\mathrm{f}$ は，Ca Iモルが 2 モルの $\mathrm{HCl}$ または 1 モルの $\mathrm{SO}_{2}$ を吸収できるとし 


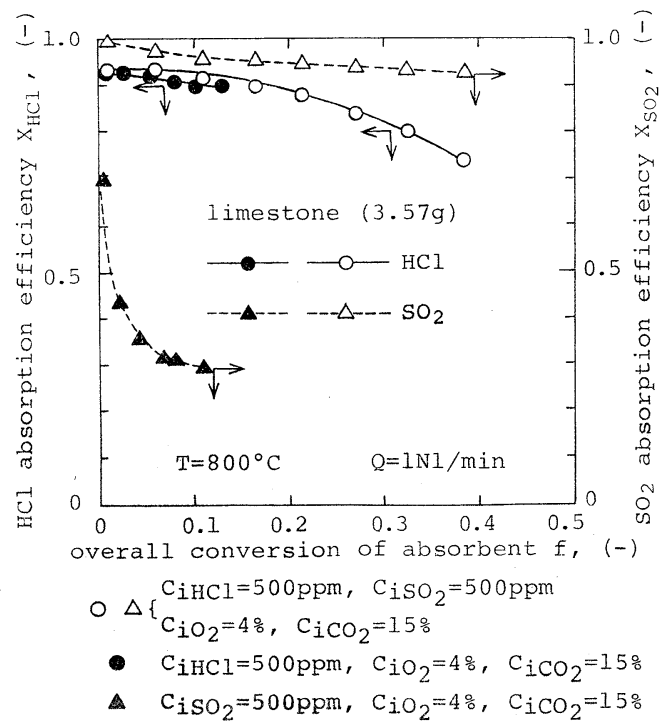

Fig. 4 Variations of HCl absorption efficiency with overall conversion of absorbents

て次式によって定義した。

$$
\mathrm{f}=\frac{10^{-6} \mathrm{Q}}{22.4 \mathrm{M}} \int_{0}^{t}\left\{\frac{1}{2} \mathrm{Ci}_{\mathrm{HCl} \cdot} \cdot \mathrm{X}_{\mathrm{HCl}(\mathrm{t})}+\mathrm{CiSO}_{2} \cdot \mathrm{X}_{\mathrm{SO}_{2}(\mathrm{t})}\right\} \mathrm{dt}
$$

ここで, $\mathrm{t}$ は吸収時間 $(\mathrm{min}), \mathrm{M}$ は充垻した試料中 の $\mathrm{Ca}$ のモル数 (mol), Qはガス流量 $(\mathrm{N} \ell / \mathrm{min})$ であ る。石灰石中の $\mathrm{Ca}$ が完全に塩化物または硫酸塩に転 化したとき， $\mathrm{f}=1$ となる。

$\mathrm{HCl}$ の吸収率には， $\mathrm{SO}_{2}$ 共存の影響がほとんど認 められない。一方， $\mathrm{SO}_{2}$ の吸収率は $\mathrm{HCl}$ が共存する 場合の方が高く，固体の反応率が 0.4 で約 $90 \%$ 以上で ある。これに対して $\mathrm{HCl}$ が共存しない場合には，初 期吸収率も低く吸収率の低下も著しくはやい。このよ らに, $\mathrm{SO}_{2}$ の吸収に対して $\mathrm{HCl}$ の存在がよい効果を 示すことがわかった。

そこで，X線マイクロアナライザー(XMA)により $\mathrm{S}$ 原子の石灰石粒子内部への吸収に特よぼす $\mathrm{HCl}$ 存 在の影響を検討した。Fig. 5 (a)には $\mathrm{HCl}$ が共存しな い場合，Fig. 5 (b) そは $\mathrm{HCl}$ が共存する場合の S 原子 の分布を示す。図中には試料粒子の破断面，ならびに XMA の走査場所と方向を示す。縦軸は，Sならびに C1 原子の信号強度を表わしている。な挔，XMA の
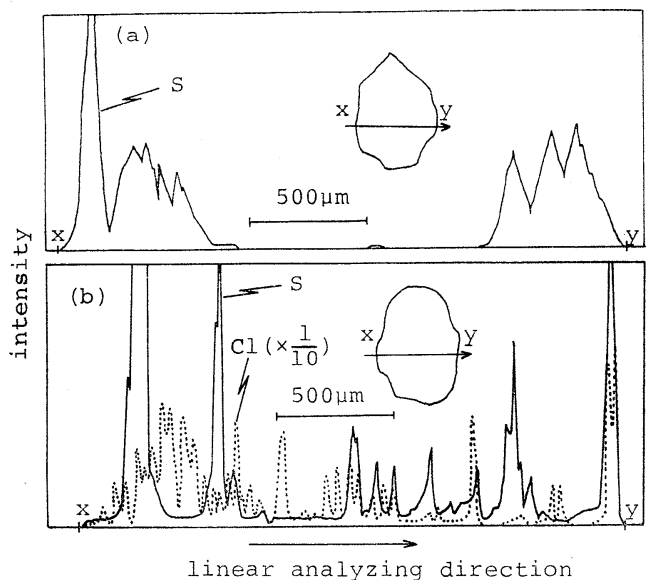

(a) $\mathrm{C}_{\mathrm{iSO}_{2}}=500 \mathrm{ppm}, \mathrm{C}_{\mathrm{iO}_{2}}=4 \%, \mathrm{C}_{\mathrm{iCO}}=15 \%$ $\mathrm{T}=800^{\circ} \mathrm{C}, Q=1 \mathrm{Nl} / \mathrm{min}$, exposure time $=7 \mathrm{hr}$

(b) $\mathrm{C}_{\mathrm{iHCl}}=500 \mathrm{ppm}, \mathrm{C}_{\mathrm{iSO}_{2}}=500 \mathrm{ppm}, \mathrm{C}_{\mathrm{iO}_{2}}=4 \%$ $\mathrm{C}_{\mathrm{iCO}}=15 \%, \mathrm{~T}=800^{\circ} \mathrm{C}, Q=1 \mathrm{NI} / \mathrm{min}$ exposure time $=7 \mathrm{hr}$

Fig. 5 Sulfur and chlorine atomic distributions on the cutting section

使用電圧は $25 \mathrm{kV}$ ，電流は約 $1 \times 10^{-8} \mathrm{~A}$ とし，Sならび に $\mathrm{Cl}$ の $\mathrm{k} \alpha$ 線を $\mathrm{PET}$ 結晶を用いて分光測定した。

Fig. 5 (a)から $\mathrm{HCl}$ が共存しない場合， S 原子はお もに粒子の表面だけで吸収され，内部ではあまり吸収 されていないことがわかる。一方，Fig. 5 (b)から $\mathrm{HCl}$ 共存の場合は粒子内部でも， $\mathrm{S}$ 原子と $\mathrm{Cl}$ 原子が吸収 されていることがわかる。したがって，Fig. 4 に示し た $\mathrm{HCl}$ 共存による $\mathrm{SO}_{2}$ 吸収率の違いは， $\mathrm{HCl}$ の影響 によって粒子内部での $\mathrm{SO}_{2}$ の吸収が増加するためで ある。

\section{3. 結 論}

石英製の小型反応管により，石灰石，ドロマイト， $\mathrm{Ni}$ 鉱石，オリビンサンドの 4 種類の試料の吸収能を 比較した結果，石灰石の吸収能がもっとも高く，层焼 しない方が高い吸収率を長時間持続することがわかっ た。石灰石は $\mathrm{HCl}$ と $\mathrm{SO}_{2}$ の同時吸収が可能であり， $\mathrm{HCl}$ が $\mathrm{SO}_{2}$ の吸収効果を高める働きのあることがわ かった。

〔謝辞】本研究にあたり，分析技術に関してご指導 を頂いた当所》鈴木良和，矢部勝昌両主任研究官に感 謝いたします。 


\section{The Search of an Absorbent for $\mathrm{HCl}$ and $\mathrm{SO}_{2}$ Removal at High Temperature}

Akira Deguchi, Yasushi Kochiyama, Hideo Hosoda, Masakatsu Miura, Toshimasa Hirama, Hiroki NishizaKi and Masayuki Horio*

$$
\left(\begin{array}{l}
\text { Gov. Industrial Development Lab., Hokkaido, } \\
\text { *Dept. of Iron and Steel Eng., Nagoya Univ. }
\end{array}\right)
$$

SYNOPSIS:- The objective of this article is to search for the absorbent to absorb $\mathrm{HCl}$ and $\mathrm{SO}_{2}$ gases in the fluidized bed combustor. The $\mathrm{HCl}$ absorption efficiency of four absorbents was measured at $800^{\circ} \mathrm{C}$, using a packed bed reactor. As a result, it was found that limestone was most effective and uncalcined limestone kept high absorption efficiency for a long exposure time, as compared with calcined one. The limestone absorbed both $\mathrm{HCl}$ and $\mathrm{SO}_{2}$ gases simultaneously, and the $\mathrm{HCl}$ gas promoted the $\mathrm{SO}_{2}$ absorption efficiency.

\section{Key Words}

$\mathrm{HCl}$ and $\mathrm{SO}_{2}$ absorptions, limestone 